\title{
PENERAPAN TEORI DIFUSI INOVASI PADA PEMBELAJARAN ORANG PENGARUH KARAKTERISTIK PETANI, PENGUATAN KAPASITAS KELOMPOK TANI DALAM USAHA PELAYANAN JASA ALAT MESIN PERTANIAN (UPJA) DI WILAYAH BPP PLAYEN GUNUNG KIDUL
}

\author{
Sukadi, Totok Sevenek Munanto \\ Politeknik Pembangunan Pertanian Yogyakarta-Magelang \\ Jl. Kusumanegara No.2, Yogyakarta, 55167 \\ Email: sukadi_stpp@Yahoo.com
}

\begin{abstract}
This study aims to determine the influence of farmer's characteristics, strengthening individual capacity, strengthening institutional capacity, strengthening network capacity for agricultural machine tool services (UPJA). Research in the district Playen, Kab. Gunungkidul, research conducted in July to December 2018, the type of quantitative research, type of primary data, sampling technique using purposive sampling, questionnaire data collection techniques, the results of the study showed that: 1) Age of respondents between 40-55 years is $46.7 \%$; 2) Education of respondents mostly high school is 53.3\%; 3) Less than 1 year UPJA experience is $70 \%$ of respondents. The results of the regression analysis that have an effect on age affect the (UPJA) value of Sig. 0.046 at the level of $5 \%$ and network capacity affects the (UPJA) value of Sig. 0.083 at the level of $10 \%$.
\end{abstract}

Keywords: influence, characteristics, capacity, UPJA

\section{PENDAHULUAN}

Sektor pertanian mempunyai peranan strategis terutama sebagai penyedia pangan rakyat Indonesia, berkontribusi nyata dalam penyediaan bahan pangan, bahan baku industri, bioenergi, penyerapan tenaga kerja yang akan berdampak pada penurunan tingkat kemiskinan dan menjaga pelestarian lingkungan. Untuk itu, kapasitas dan kemampuan Pelaku Utama dan Pelaku Usaha terus ditingkatkan, salah satunya melalui penyuluhan dengan pendekatan pembinaan kelembagaan petani yang mencakup penumbuhan dan pengembangan kelembagaan petani, sehingga petani dapat berkumpul untuk menumbuhkembangkan kelembagaannya menjadi Kelembagaan Ekonomi Petani (KEP) yang berdaya saing tinggi, produktif, menerapkan tata kelola berusaha yang baik, dan berkelanjutan.
Karakteristik individu dapat diklasifikasikan ke dalam karakteristik demograsi dan psikografi. Karakteristik demografi mencakup umur, jenis kelamin, ukuran keluarga, penghasilan, pekerjaan, pendidikan dan tingkat sosial, sedangkan karakteristik psikografi meliputi gaya hidup dan kepribadian ini akan mempengaruhi persepsi (Rona, 1999). Penguatan kapasitas adalah proses peningkatan kemampuan individu, kelompok, organisasi dan kelembagaan yang lain untuk memahami dan melaksanakan pembangunan dalam arti luas secara berkelanjutan (Mardikanto, 2010). Kapasitas adalah kemampuan baik individu, kelompok, organisasi dan kelembagaan yang lain untuk menunjukkan ataupun memerankan fungsinya secara efektif, efisien dan berkelanjutan.

Penguatan kelembagaan petani sangat 
diperlukan dalam rangka perlindungan dan pemberdayaan petani. Oleh karena itu, petani dapat menumbuhkembangkan kelembagaan dari, oleh, dan untuk petani guna memperkuat dan memperjuangkan kepentingan petani itu sendiri sesuai dengan perpaduan antara budaya, norma, nilai, dan kearifan lokal petani. Kelompok Tani yang selanjutnya disebut Poktan adalah kumpulan petani/peternak/pekebun yang dibentuk oleh para petani atas dasar kesamaan kepentingan, kesamaan kondisi lingkungan sosial, ekonomi, dan sumberdaya, kesamaan komoditas, dan keakraban untuk meningkatkan dan mengembangkan usaha anggota. Usaha Pelayanan Jasa Alat dan Mesin Pertanian yang selanjutnya disebut UPJA adalah suatu lembaga ekonomi pedesaan yang bergerak di bidang pelayanan jasa dalam rangka optimalisasi penggunaan alat dan mesin pertanian untuk mendapatkan keuntungan usaha baik di dalam maupun di luar kelompok tani/gapoktan.

Penguatan kapasitas kelompok tani dalam usaha pelayanan jasa alat mesin pertanian(UPJA) di wilayah Balai Penyuluhan Pertanian (BPP) Playen Gunung Kidul dengan pertimbangan wilayah tersebut merupakan BPP Mitra dari Politeknik Pembangunan Pertanian (POLBANGTAN) YogyakartaMagelang. Wilayah Kerja Balai Penyuluhan Pertanian (WKBPP) Playen meliputi satu wilayah Kecamatan Playen, terdiri dari 13 desa. Jumlah kelompok tani diwilayah BPP Playen sebanyak 103 kelompok tani. Setiap kelompok tani sebagaian besar telah memiliki alat mesin pertanian berupa traktor, pompa air, cultivator, power thraser, sprayer. Alat mesin pertanian tersebut belum digunakan belum maksimal (sebagian besar baru dipakai untuk kelompok taninya sendiri dan kurang berkembang).

Berdasarkan uraian di tersebut perlu di lakukan penelitian yang berjudul Pengaruh Karakteristik Petani, Penguatan Kapasitas Kelompok tani dalam Usaha Pelayanan Jasa Alat Mesin Pertanian di Wilayah Balai Penyuluhan Pertanian (BPP) Playen Kabupaten Gunung Kidul DIY. Rumusan Masalah bagaimana pengaruh karakteristik petani, penguatan kapasitas kelompok tani dalam Usaha Pelayanan Jasa Alat Mesin Pertanian. Tujuan penelitian untuk mengetahui pengaruh karakteristik petani, penguatan kapasitas kelompok tani dalam Usaha Pelayanan Jasa Alat Mesin Pertanian.

Karakteristik individu dapat diklasifikasikan ke dalam karakteristik demografi dan psikografi. Karakteristik demografi mencakup umur, jenis kelamin, ukuran keluarga, penghasilan, pekerjaan, pendidikan dan tingkat sosial, sedangkan karakteristik psikografi meliputi gaya hidup dan kepribadian. ini akan mempengaruhi persepsi Rona (1999).

Umur petani erat hubungannya dengan kemampuan fisik, petani yang sudah tua kemungkinan kekuatan bekerja akan berkurang (Yusri, 1999). Petani yang berumur muda memiliki wawasan dan pandangan ke depan yang lebih baik dibandingkan dengan kelompok umur tua. Petani yang sudah tua cenderung daya tahan tubuhnya sudah berkurang, sehingga kemampuan berpartisipasi dalam berbagai kegiatan penyuluhan akan berkurang. Difusi inovasi yang paling tinggi adalah pada mereka yang berumur setengah tua. Orang yang berumur 
lebih muda biasanya akan lebih bersemangat dibandingkan dengan yang lebih tua (Soekartawi, 1988).

Tingkat pendidikan mempunyai pengaruh yang langsung dan nyata terhadap penerapan teknik dalam penyuluhan. Semakin tinggi tingkat pendidikan seseorang, semakin efisien dalam bekerja dan semakin banyak mengetahui cara berusahatani yang lebih produktif dan lebih menguntungkan (Soeharjo dan Patong, 1973).

Pendidikan yang dimaksud adalah pendidikan formal yang diikuti oleh petani. Petani yang berpendidikan tinggi lebih mempunyai kemampuan untuk memberikan ide atau saran dalam diskusi, penyusunan rencana kerja dan juga mencari dan memberi informasi untuk kepentingan anggota kelompok lain (Akhiyar, 1994).

Petani yang berpengalaman akan lebih bijak saat menerima atau menolak suatu inovasi. Mengambil suatu keputusan tentang berbagai masalah, seseorang sangat dipengaruhi oleh pengalaman-pengalaman di masa lampu, kecakapan dan asumsi mengenai situasi tertentu (Kirana 2007).

\section{Penguatan Kapasitas Kelompok Tani}

Kapasitas adalah kemampuan (individu, kelompok, organisasi, dan kelembagaan yang lain) untuk menunjukkan fungsinya secara efektif, efisien dan berkelanjutan, kapasitas bukanlah sesuatu yang pasif, melainkan proses yang berkelanjutan, pengembangan kapasitas sumberdaya manusia merupakan pusat pengembangan kapasitas, (Mardikanto, 2010)

Pengembangan kapasitas individu, adalah segala upaya untuk memperbaiki atau mengembangkan mutu karakteristik pribadi agar lebih efektif dan efisien, baik didalam entitasnya maupun dalam lingkup global. Pengembangan kapasitas pribadi meliputi, pengembangan kapasitas kepribadian, kapasitas di dunia kerja dan pengembangan keprofesionalan. Pengembangan kapasitas entitas/organisasi lebih ditekankan kepada pengembangan mutu entitas/organisasi. Kapasitas dimaksud meliputi, kejelasan visi, misi dan budaya organisasi, struktur organisasi, kompetensi dan strategi. Aspek lain adalah tujuan organisasi, efektivitas organisasi, proses organisasi, mutu sumberdaya, interaksi antar individu didalam organisasi (Mardikanto, 2010)

Penguatan kapasitas adalah proses peningkatan kemampuan individu, kelompok, organisasi dan kelembagaan yang lain untuk memahami dan melaksanakan pembangunan dalam arti luas secara berkelanjutan (Mardikanto, 2010). Dalam pengutipan tersebut terkandung maksud bahwa yang dimaksud dengan kapasitas adalah kemampuan baik individu, kelompok, organisasi dan kelembagaan yang lain untuk menunjukkan ataupun memerankan fungsinya secara efektif, efisien dan berkelanjutan (Mardikanto, 2010).

Penguatan kelembagaan petani sangat diperlukan dalam rangka perlindungan dan pemberdayaan petani. Oleh karena itu, petani dapat menumbuhkembangkan kelembagaan dari, oleh, dan untuk petani guna memperkuat dan memperjuangkan kepentingan petani itu sendiri sesuai dengan perpaduan antara budaya, norma, nilai, dan kearifan lokal petani (Mardikanto, 2010).

Penguatan kelembagaan perlu dilakukan melalui beberapa upaya, antara 
lain; (1) mendorong dan membimbing petani agar mampu bekerjasama di bidang ekonomi secara berkelompok, (2) menumbuhkembangkan kelompok tani melalui peningkatan fasilitasi bantuan dan akses permodalan, peningkatan posisi tawar, peningkatan fasilitasi dan pembinaan kepada organisasi kelompok, dan peningkatan efisiensi dan efektivitas usahatani, serta (3) meningkatkan kapasitas SDM petani melalui berbagai kegiatan pendampingan, dan latihan yang dirancang secara khusus bagi pengurus dan anggota (Hermantoe, et al. 2011).

Untuk mencapai keberdayaan tersebut, program pemberdayaan kelompok tani yang dilakukan harus dapat meningkatkan kemampuan kelompok tani dalam hal; (1) memahami kekuatan (potensi) dan kelemahan kelompok; (2) memperhitungkan peluang dan tantangan yang dihadapi, pada saat ini dan masa mendatang; (3) memilih berbagai alternatif yang ada untuk mengatasi masalah yang dihadapi, dan (4) menyelenggarakan kehidupan berkelompok dan bermasyarakat yang serasi dengan lingkungannya secara berkesinambungan (Hermantoe, et al. 2011).

Kelembagaan Petani adalah lembaga yang ditumbuhkembangkan dari, oleh, dan untuk petani guna memperkuat dan memperjuangkan kepentingan petani, mencakup Kelompok Tani, Gabungan Kelompok Tani, Asosiasi Komoditas Pertanian, dan Dewan Komoditas Pertanian Nasional (Menteri Pertanian, 2016).

Kelompok Tani yang selanjutnya disebut Poktan adalah kumpulan petani/ peternak/pekebun yang dibentuk oleh para petani atas dasar kesamaan kepentingan, kesamaan kondisi lingkungan sosial, ekonomi, dan sumberdaya, kesamaan komoditas, dan keakraban untuk meningkatkan dan mengembangkan usaha anggota (Menteri Pertanian, 2016).

\section{Usaha Pelayanan Jasa Alat dan Mesin Pertanian}

Usaha Pelayanan Jasa Alat dan Mesin Pertanian yang selanjutnya disebut UPJA adalah suatu lembaga ekonomi perdesaan yang bergerak di bidang pelayanan jasa dalam rangka optimalisasi penggunaan alat dan mesin pertanian untuk mendapatkan keuntungan usaha baik di dalam maupun di luar kelompok tani/gapoktan (Menteri Pertanian, 2008)

Alat dan Mesin Pertanian (Alsintan) mempunyai peranan yang sangat penting dan strategis dalam rangka mendukung pemenuhan produksi pertanian yang terus meningkat sejalan dengan pertambahan jumlah penduduk, menurunnya daya dukung lahan, rendahnya intensitas pertanaman, dan kepemilikan alsintan secara individu yang kurang menguntungkan. Hal ini mutlak diperlukan, dikarenakan Alsintan dapat mempercepat dan meningkatkan mutu pengolahan tanah, penyediaan air, meningkatkan intensitas Pertanaman (IP), meningkatkan produktivitas ternak, mengurangi kehilangan hasil, menjaga kesegaran dan keutuhan, meningkatkan nilai tambah melalui pengolahan produk komoditas pertanian dan melestarikan fungsi lingkungan (Menteri Pertanian, 2008).

Untuk itu, strategi pengembangan alsintan dalam rangka pemanfaatan inovasi dan teknologi mekanisasi pertanian dengan menumbuh dan mengembangkan sistem kelembagaan Usaha Pelayanan Jasa 
Alsintan (UPJA), dengan pertimbangan : (1) Kemampuan petani dalam mengolah lahan usahatani terbatas $(0,5 \mathrm{ha} / \mathrm{MT})$;

Pengelolaan Alsintan secara perorangan kurang efisien; (3) Tingkat pedidikan dan ketrampilan petani yang rendah; (4) Kemampuan permodalan usahatani yang lemah; dan (5) Pengelolaan usahatani yang tidak efisien. Sedangkan fungsi utama kelembagaan UPJA yaitu melakukan kegiatan ekonomi dalam bentuk pelayanan jasa alsintan dalam penanganan budidaya seperti jasa penyiapan lahan dan pengolahan tanah, pemberian air irigasi, penanaman, pemeliharaan; perlindungan tanaman termasuk pengendalian kebakaran; maupun kegiatan panen, pasca panen dan pengolahan hasil pertanian seperti jasa pemanenan, perontokan, pengeringan dan penggilingan padi; termasuk mendorong pengembangan produk dalam rangka peningkatan nilai tambah, perluasan pasar, daya saing dan perbaikan kesejahteraan petani.

\section{METODE PENELITIAN}

Penelitian ini dilakukan di Kelompok Tani wilayah BPP Playen, DIY. Waktu kegiatan antara bulan Juli sampai dengan Desember 2018. Penentuan responden dilakukan secara purposive sampling dengan perincian sebagai berikut: Dari 103 kelompok tani diambil kelompok yang mempunyai UPJA, Jumlah responden secara keseluruhan sebanyak 30 orang yang melaksanakan UPJA. Pengumpulan data primer diperoleh dengan kuesioner. Analisis data yang digunakan dalam penelitian ini adalah metode deskriptif sedangkan untuk melihat pengaruh antara variabel penelitian digunakan uji statistik regresi.

\section{HASIL PENELITIAN DAN PEMBA- HASAN \\ - Umur Responden (pengelola UPJA)}

Table 1. Distribusi Frekuensi Umur (X1) Responden.

\begin{tabular}{clcc}
\hline & & Frequency & Percent \\
\hline \multirow{3}{*}{ Valid } & $\leq 40$ & 11 & 36.7 \\
& $40-55$ & 14 & 46.7 \\
& $\geq 55$ & 5 & 16.7 \\
\cline { 2 - 4 } & Total & 30 & 100.0 \\
\hline
\end{tabular}

Sumber: oleh data primer, 2018

Sebagian besar responden 46,7 \% berumur antara 40-55 tahun, menurut Departemen Kesehatan RI (2009) masuk katategori masa dewasa akhir 36-45 tahun dan masa lansia awal 46-55 tahun, ini berarti bahwa petani/responden pengelola usaha pelayanan jasa alat dan mesin pertanian (UPJA) di Kecamatan Playen masih efektif dalam mengembangan usala pelayanan jasa alat mesin pertanian hal ini sejalan dengan pendapat (Soekartawi, 1988) difusi inovasi yang paling tinggi adalah pada mereka yang berumur setengah tua. ini menunjukkan bahwa usia dimaksud akan mendukung kegiatan dan pengembangan usaha pelayanan jasa alat mesin pertanian di Kecamatan Playen.

\section{- Pendidikan Responden (pengelola} UPJA)

Table 2. Distribusi Frekuensi Tingkat Pendidikan (X2) Responden.

\begin{tabular}{clcc}
\hline & & Frequency & Percent \\
\hline Valid & SD & 2 & 6.7 \\
& SMP & 9 & 30.0 \\
& SMA & 16 & 53.3 \\
& S1 & 3 & 10.0 \\
\cline { 2 - 4 } & Total & 30 & 100.0 \\
\hline
\end{tabular}

Sumber: oleh data primer, 2018 
Sebagian besar responden 53,3\% tingkat pendidikan Sekolah Menengah Atas (SMA), hal ini menunjukkan bahwa tingkat pendidikan dimaksud dapat mendukung dalam usaha pengembangan usaha jasa alat mesin pertanian sejalan dengan pendapat (Soeharjo dan Patong, 1973). Semakin tinggi tingkat pendidikan seseorang, semakin efisien dalam bekerja dan semakin banyak mengetahui cara berusahatani yang lebih produktif dan lebih menguntungkan. Petani yang berpendidikan tinggi lebih mempunyai kemampuan untuk memberikan ide atau saran dalam diskusi, penyusunan rencana kerja dan juga mencari dan memberi informasi untuk kepentingan anggota kelompok lain (Akhiyar, 1994). Pendidikan petani SMA pada petani cukup tinggi sehingga dapat meningkatkan efisiensi usaha dan mengembangkan usaha pelayanan jasa alat masin pertanian (UPJA).

- Pengalaman Responden (pengelola UPJA)

Table 3. Distribusi Frekuensi Pengalaman UPJA (X3) Responden.

\begin{tabular}{cccc}
\hline & & Frequency & Percent \\
\hline Valid & $<1$ tahun & 21 & 70.0 \\
& $1 \mathrm{~s} / \mathrm{d} 2$ tahun & 6 & 20.0 \\
& $>2$ tahun & 3 & 10.0 \\
\cline { 2 - 4 } & Total & 30 & 100.0
\end{tabular}

Sumber: oleh data primer, 2018

Sebagian besar responden 70\% mempunyai pengalaman usaha jasa alat mesin pertanian kurang dari 1 tahun, ini menunjukan bahwa Usaha pelayanan jasa alat mesin pertanian (UPJA) baru saja dibentuk setelah mendapatkan pelatihan. Pendapat (Kirana 2007) pengambilan suatu keputusan tentang berbagai masalah, seseorang sangat dipengaruhi oleh pengalaman-pengalaman di masa lampu, kecakapan dan asumsi mengenai situasi tertentu.

\section{- Kapasistas Individu (UPJA)}

Table 4. Distribusi Frekuensi Penguatan Kapasitas Individu Responden (X4)

\begin{tabular}{cccc}
\hline & & Frequency & Percent \\
\hline \multirow{7}{*}{ Valid } & Rendah & 5 & 16.7 \\
& Sedang & 23 & 76.7 \\
& Tinggi & 2 & 6.7 \\
\cline { 2 - 4 } & Total & 30 & 100.0 \\
\hline
\end{tabular}

Sumber: oleh data primer, 2018

Sebagian besar responden 76,7 \% kategori sedang kemampuan individu lama kelompok masih perlu peningkatan supaya dapat untuk meningkatkan fungsi usaha pelayanan jasa alat dan mesin pertanian (UPJA) secara efektif dan efisien. Sejalan dengan pendapat (Mardikanto, 2010) Kapasitas individu adalah kemampuan individu untuk menunjukkan fungsinya secara efektif, efisien dan berkelanjutan, kapasitas bukanlah sesuatu yang pasif, melainkan proses yang berkelanjutan, pengembangan kapasitas sumberdaya manusia merupakan pusat pengembangan kapasitas.

\section{- Kapasitas Kelembagaan (UPJA)}

Table 5. Distribusi Frekuensi Penguatan Kapasitas Kelembagaan Responden (X5)

\begin{tabular}{llcc}
\hline & & Frequency & Percent \\
\hline \multirow{7}{*}{ Valid } & Rendah & 4 & 13.3 \\
& Sedang & 16 & 53.3 \\
& Tinggi & 10 & 33.3 \\
\cline { 2 - 4 } & Total & 30 & 100.0
\end{tabular}

Sumber: oleh data primer, 2018

Sebagian besar responden 53,3\% kategori sedang masih perlu peningkatan agar kapasitas kelembagaan usaha pelayanan jasa alat mesin (UPJA) seluruh komponen organisasi (UPJA) Penguatan kelembagaan petani sangat diperlukan dalam rangka penumbuhandanpengembangankelembagaan sejalan dengan pendapat (Mardikanto, 
2010) petani dapat menumbuhkembangkan kelembagaan dari, oleh, dan untuk petani guna memperkuat dan memperjuangkan kepentingan petani itu sendiri sesuai dengan perpaduan antara budaya, norma, nilai, dan kearifan lokal petani.

\section{- Kapasitas Jejaring (UPJA)}

Table 6. Distribusi Frekuensi Penguatan Kapasitas Jejaring Responden (X6)

\begin{tabular}{cccc}
\hline \multirow{7}{*}{ Valid } & & Frequency & Percent \\
\cline { 2 - 4 } & Rendah & 8 & 26.7 \\
& Sedang & 16 & 53.3 \\
& Tinggi & 6 & 20.0 \\
\cline { 2 - 4 } & Total & 30 & 100.0
\end{tabular}

Sumber: oleh data primer, 2018

Sebagian besar responden 53,3 \% kategori sedang kemampuan berinteraksi dengan lembaga bisnis lain masih sedang perlu peningkatan, penguatan kapasitas jejaring pada usaha pelayanan jasa alat mesin (UPJA) proses peningkatan fungsinya secara efektif, efisien serta berkelanjutan sejalan pendapat (Mardikanto, 2010) kapasitas adalah kemampuan baik individu, kelompok, organisasi dan kelembagaan yang lain untuk menunjukkan ataupun memerankan fungsinya secara efektif, efisien dan berkelanjutan.
- Usaha Jasa Alat Mesin Pertanian (UPJA)

Table 7. Distribusi Frekuensi Usaha Jasa Alat

\begin{tabular}{clcc}
\multicolumn{3}{c}{ Mesin Pertanian (UPJA) } & $(\mathrm{Y})$ \\
\hline \multirow{6}{*}{ Valid } & & Frequency & Percent \\
\cline { 2 - 3 } & Rendah & 7 & 23.3 \\
& Sedang & 14 & 46.7 \\
& Tinggi & 9 & 30.0 \\
\cline { 2 - 4 } & Total & 30 & 100.0 \\
\hline
\end{tabular}

Sumber: oleh data primer, 2018

Sebagian besar responden 46,7 \% kategori sedang Usaha Jasa Pelayanan alat mesin pertanian, mempunyai peranan yang sangat penting dan strategis dalam rangka mendukung pemenuhan produksi pertanian yang terus meningkat sejalan dengan pertambahan jumlah penduduk, menurunnya daya dukung lahan, rendahnya intensitas pertanaman, dan kepemilikan alsintan secara individu yang kurang menguntungkan. Hal ini mutlak diperlukan, dikarenakan Alsintan dapat mempercepat dan meningkatkan mutu pengolahan tanah, penyediaan air, meningkatkan intensitas Pertanaman (IP), meningkatkan produktivitas ternak, mengurangi kehilangan hasil, menjaga kesegaran dan keutuhan, meningkatkan nilai tambah melalui pengolahan produk komoditas pertanian dan melestarikan fungsi lingkungan (Menteri Pertanian. 2008).

- Nilai Korelasi kontribusi X1 umur, X2 pendidikan, X3 Pengalaman, X4 Kapasitas individu, X5 kapasistas kelembagaan, X6 Kapasitas jejaring terhadap Y Usaha pelayanan jasa alat mesin pertanian (UPJA)

Table 8. Nilai Korelasi kontribusi X1, X2, X3, X4, X5, X6 terhadap Y

\begin{tabular}{lrrrr}
\hline Model & R & R Square & Adjusted R Square & Std. Error of the Estimate \\
\hline 1 & $.581^{\mathrm{a}}$ & .338 & .165 & 3.11592 \\
\hline Sumber: oleh data primer, 2018 & & & &
\end{tabular}

Nilai keeratan hubungan seluruh dependen atau korelasi berganda (R) sebesar variable independen terhadap variable 0,581. Nilai keeratan hubungan/korelasi (R) 
tergolong sedang. Nilai kontribusi seluruh variable independen terhadap variable dependen dalam model regresi sebesar 0,581 atau sebesar 58,1\% selebihnya merupakan pengaruh variable lain diluar variable penelitian.

- Analisis pengaruh masing-masing variable X1 umur, X2 pendidikan, X3 Pengalaman, X4 Kapasitas individu, X5 kapasistas kelembagaan, X6 Kapasitas jejaring terhadap Y Usaha pelayanan jasa alat mesin pertanian (UPJA)

Table 9. Hasil analisis pengaruh masing-masing variable X1, X2, X3, X4,X5,X6 terhadap Y

\begin{tabular}{|c|c|c|c|c|c|c|}
\hline & \multirow{2}{*}{ Model } & \multicolumn{2}{|c|}{ Unstandardized Coefficients } & \multirow{2}{*}{$\frac{\text { Standardized Coefficients }}{\text { Beta }}$} & \multirow{2}{*}{$\mathrm{t}$} & \multirow{2}{*}{ Sig. } \\
\hline & & B & Std. Error & & & \\
\hline \multirow[t]{7}{*}{1} & (Constant) & 17.856 & 7.290 & & 2.449 & .022 \\
\hline & Umur (X1) & -.135 & .064 & -.404 & -2.106 & .046 \\
\hline & Pendidikan (X2) & .159 & .930 & .035 & .171 & .866 \\
\hline & PengUPJA (X3) & .387 & .473 & .149 & .818 & .422 \\
\hline & Kelembagaan (X5) & -.111 & .174 & -.168 & -.639 & .529 \\
\hline & Individu (X4) & -.032 & .304 & -.026 & -.104 & .918 \\
\hline & Jejaring (X6) & .646 & .357 & .374 & 1.810 & .083 \\
\hline
\end{tabular}

Sumber: oleh data primer, 2018

Berdasarkan tabel 9, diperoleh nilai Sig. umur $=0,046$ yang berarti $<$ kriteria signifikan $(0,05)$, dengan demikian umur perpengaruh kepada usaha pelayanan jasa alat mesin pertanian, sekain muda umurnya semakin baik pada taraf 5\%. Sejalan pendapat (Soekartawi, 1988) Orang yang berumur lebih muda biasanya akan lebih bersemangat dibandingkan dengan yang lebih tua. Dalam hal ini yang umurnya lebih muda lebih bersemangat dalam mengembangan Usaha Pelayanan Jasa Alat dan Mesin pertanian (UPJA).

Selain umur yaitu jejaring, diperoleh nilai Sig. jejaring $=0,083$ yang berarti $<$ kriteria signifikan $(0,1)$, dengan demikian kapasitas jejaring berpengaruh kepada usaha pelayanan jasa alat mesin pertanian, semakin jaringannya luas semakin baik pada taraf $10 \%$. Semakin luas jejaring semakin baik usaha pelayanan jasa alat mesin pertanian karena lebih banyak yang menggunakan jasa alat mesin pertanian sejalan pendapat (Mardikanto, 2010) kapasitas adalah kemampuan baik jejaring yang lain untuk menunjukkan ataupun memerankan fungsinya secara efektif, efisien dan berkelanjutan.

\section{KESIMPULAN DAN SARAN}

Kesimpulan dari hasil penelitian sebagai berikut:

1. Umur antara 40-55 tahun Sebagian besar responden $46,7 \%$, menurut masih efektif dalam mengembangan UPJA.

2. Pendidikan Sekolah Menengah Atas (SMA Sebagian besar responden 53,3 $\%$ tingkat), cukup tinggi sehingga dapat meningkatkan efisiensi usaha dan mengembangkan (UPJA).

3. Pengalaman usaha jasa alat mesin pertanian kurang dari 1 tahun sebagian besar responden $70 \%$ sebagian besar baru saja di bentuk.

4. Umur berpengaruh terhadap usaha 
jasa alat mesin pertanian (UPJA) nilai

Sig. umur $=0,046$ yang berarti $<$ kriteria signifikan $(0,05)$ usianya lebih muda lebih bersemangat.

5. Penguatan kapasitas jejaring berpengaruh terhadap usaha jasa alat mesin pertanian (UPJA) nilai Sig. jejaring $=0,083$ yang berarti $<$ kriteria signifikan $(0,1)$ Semakin luas jejaring semakin baik usaha pelayanan jasa alat mesin pertanian karena lebih banyak yang menggunakan jasa alat mesin pertanian .

\section{Saran}

1. Untuk pengembangan usaha pelayanan jasa alat mesin pertanian sebaiknya petani muda.

2. Untuk pengembangan usaha pelayanan jasa alat mesin pertanian sebaiknya selalu mengembangan kapasitas jejaring usaha.

\section{DAFTAR PUSTAKA}

Akhyar, 1994. Dekonstruki Epistemologi Modern: Dari Posmodernisme, Teori Kritis, Soskolonialisme Hingga Cultural Studies. Jakarta: Pustaka Indonesia Satu.

Hermanto dan Dewa K.S. Swastika. 2011. Penguatan Kelompok Tani: Langkah Awal Peningkatan Kesejahteraan Petani. Bogor. Pusat Sosial Ekonomi dan Kebijakan Pertanian. Analisis Kebijakan Pertanian. Volume 9 No. 4.

Kirana. 2007. Pengantar Tekhnik Penyuluhan. Jakarta: Raja Grafindo Persada.

Mardikanto, T, 2009, Sistem Penyuluhan
Pertanian, Sebelas Maret University Press. Surakarta.

Mardikanto, T,2010, Konsep-Konsep Pemberdayaan Masyarakat, Sebelas Maret University Press. Surakarta.

Mardikanto, T, 2010. Model-Model Pemberdayaan Masyarakat, Sebelas Maret Universty Press. Surakarta.

Menteri Pertanian. 2008. Peraturan Menteri Pertanian Nomor 25/Permentan/ PL.130/5/2008. Tentang. Pedoman Penumbuhan dan Pengembangan Usaha Pelayanan Jasa Alat dan Mesin Pertanian. Jakarta.

Menteri Pertanian. 2016. Peraturan Menteri PertanianRepublik Indonesia Nomor 67/PERMENTAN/SM.050/12/2016 Tentang Pembinaan Kelembagaan Petani. Berita Negara Republik Indonesia Tahun 2016 Nomor 2038. Jakarta.

Rona S. 1999. Hubungan Karakteristik Petani dengan Tingkat Partisipasinya sebagai anggota Kelompok Tani. Skripsi. Fakultas Pertanian. Institut Pertanian Bogor. Bogor.

Soeharjo, A dan Patong. 1973. Sendi - Sendi Pokok Usahatani. Jurusan Ilmu Sosial Ekonomi Pertanian. Institut Pertanian Bogor : Bogor

Soekartawi. 1988. Ilmu Usahatani dan Penelitian untuk Pengembangan Pertanian Kecil. Jakarta: UI Press

Yusri, A. 1999. Faktor-Faktor Yang Mempengaruhi Persepsi Petani Terhadap Kredibilitas Penyuluhan Pertanian. Tesis. Program Pascasarjana. Institut Pertanian Bogor. Bogor. 